
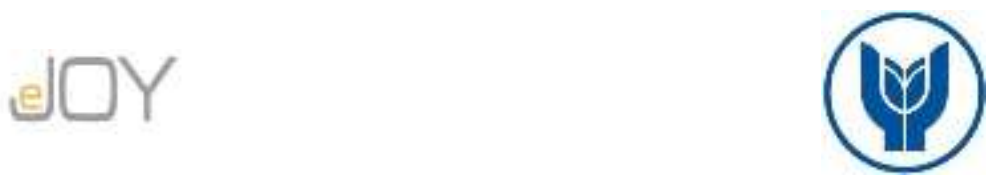

Türkay, M. / Journal of Yasar University, 2020, 15/60, 692-707

\title{
Kamu Borcu ve Büyüme İlişkisi: Heterojen Panel Veri Analizi
}

\section{Public Debt and Growt h Relationship: Heterogenous Panel Data Analysis}

\author{
Mesut TÜRKAY, Hazine ve Maliye Bakanlığı, Türkiye, mesut.turkay@hmb.gov.tr
}

Orcid No: 0000-0002-3364-385X

Öz: Çalışmanın amacı kamu borcuyla ekonomik büyüme arasındaki ilişkiyi analiz etmektir. Bu amaçla, gelişmiş ve gelişmekte olan 43 ülkeyi içeren panel veri setiyle, yatay kesit bağımlılı̆̆ ve ĕğim katsayısının heterojenliğini dikkate alan ortak ilişkili etkiler (CCE) ve genişletilmiş ortalama grup (AMG) tahmin edicileri kullanılmıştır. Model sonuçlarına göre, kamu borç stoku ile büyüme arasındaki ilişki ülke gruplarına göre değişmektedir. Gelişmiş ülkeler için kamu borcu ve büyüme ilişkisi pozitif olarak bulunurken, gelişmekte olan ülkeler için ise söz konusu ilişkinin negatif olduğu sonucuna ulaşılmıştır.

Anahtar Sözcükler: Kamu Borcu, Ortak İlişkili Etkiler, Heterojenlik, Yatay Kesit Bă̆ımlılı̆̆l

JEL Siniflandırması: C23, E32, H63

Abstract: The objective of the study is to analyze the relationship between public debt and economic growth. For this purpose, with a panel data set consisting of 43 advanced and emerging market countries, common correlated effects (CCE) and augmented mean group (AMG) estimators that take into account cross section dependence and heterogeneity of slope coefficient are used. Model results show that the relationship between public debt stock and growth varies according to country groups. While the relationship between public debt and growth was found to be positive for developed countries, it was concluded that the relationship was negative for developing countries.

Keywords: Public Debt, Common Correlated Effect, Heterogeneity, Cross Section Dependence

JEL Classification: C23, E32, H63

\section{Giriş}

2019 yılının sonlarında Çin'de ortaya çıkıp 2020 yılının ilk aylarında tüm dünyaya yayılan koronavirüs nedeniyle tüm dünyada ekonomik aktivite olumsuz bir biçimde etkilenmiştir. Politika yapıcılar salgının etkilerini azaltmak ve tekrar büyüme sürecine dönebilmek amacıyla kapsamlı önlem paketlerini devreye sokmuşlardır. Merkez bankaları faiz oranlarını düşürmüş, varlık alım programları açıklamış ve piyasalara gerekli likiditeyi sağlamışlardır. Hükümetler salgından etkilenen işletme ve vatandaşlara yönelik nakit transferleri, vergi ve sosyal güvenlik ödemelerinin ötelenmesi, işsizlik ödeneklerinin artırılması, düşük faizli kredi sağlanması gibi önemli adımlar atmışlardır. $\mathrm{Bu}$ süreçte, ekonomik aktivitenin azalması nedeniyle vergi gelirleri azalırken, alınan önlemlerin sonucu olarak kamu harcamaları artış eğilimine girmiştir. Bunun sonucunda tüm dünyada bütçe açı̆̆ı ciddi anlamda yükselmiş, kamu borcu

\section{Makale Gecmiși / Article History}

Başvuru Tarihi / Date of Application Kabul Tarihi / Acceptance Date

(C) 2020 Journal of Yaşar University. Published by Yaşar University. Journal of Yaşar University is an open access journal.

There is no conflict of interest or ethical concern regarding this publication. 
rekor seviyelere yükselmiştir. IMF (2020) dünyada kamu borç stokunun milli gelire oranının 2020 yılında tarihi en yüksek seviye olan yüzde 100 düzeyine ulaşacağını tahmin etmektedir.

Atılan adımlar kısa vadede ekonomik büyümeyi pozitif anlamda etkilese de, bu sürecin sonucunda ciddi anlamda artacak olan kamu borcunun büyüme üzerindeki orta-uzun vadeli etkileri de büyük önem arz etmektedir. Bu motivasyonla hareket ederek, çalışmada kamu borcuyla büyüme arasındaki ilişki yatay kesit bağımlılı̆̆ı ve eğim katsayısının heterojenliğini dikkate alan güncel ekonometrik yöntemler kullanarak analiz edilecektir. Ülkelerin ekonomik, finansal, kültürel ve kurumsal yapıları birbirinden çok farklı olması nedeniyle eğim katsayısının ülkeden ülkeye değişmesi beklenen bir sonuçtur. Diğer taraftan, küresel finans krizi, emtia fiyat şokları ve günümüzde yaşadığımız virüs salgını gibi her ülkeyi etkileyen ortak küresel faktörler nedeniyle yatay kesit bağımlığı ortaya çıkmaktadır. Çalışmamızda, Pesaran (2006) tarafından geliştirilen ortak ilişskili etkiler (common correlated effects, CCE) tahmin edicisi ile Eberhardt ve Bond (2009) tarafından geliştirilen genişletilmiş ortalama grup tahmin edicileri kullanılmaktadır. Kullanılan bu tahmin ediciler yatay kesit bağımlılığını, heterojen eğim katsayısını ve içselliği dikkate almaktadır.

$\mathrm{Bu}$ çalışmanın literatüre birçok farklı açıdan katkısı bulunmaktadır. Öncelikle, makro panel veri analizi hala büyük ölçüde mikro veri setleri için geliştirilmiş olan tahmin edicilerle yapılmaktadır. Bunların başında Arellano ve Bond (1991) ile Blundell ve Bond (1998) tarafından geliştirilmiş olan dinamik panel veri tahmin edicileri gelmektedir. Veriye artan ulaşımla birlikte, panel literatürü giderek yatay kesit boyutunun $(\mathrm{N})$ geniş, zaman serisi boyutunun (T) küçük olduğu mikro panellerden hem yatay kesit hem de zaman serisi boyutunun büyük olduğu makro panellere doğru kaymaktadır. Bu çalışmada, Barro (1990), Mankiw vd. (1992) ve Baldacci ve Kumar (2010) gibi literatürdeki birçok çalışmanın aksine, hem yatay kesit hem de zaman serisi boyutunun büyük olduğu durumda güçlü olan makro panel veri tahmin edicileri kullanılmaktadır.

İkincisi, literatürdeki mevcut çalışmaların büyük çoğunluğu homojen eğim katsayısı ve yatay kesit bağımsızlığı varsayımında bulunmaktadır. Panel veri ekonometrisindeki önemli gelişmelere rağmen, ampirik literatürde yatay kesit bağımlılı̆̆ı ve eğim katsayısının heterojenliğini dikkate alan panel zaman serisi yöntemleri uygulayan göreceli olarak az sayıda çalışma bulunmaktadır. Çalışmamızın literatüre önemli katkılarından biri yatay kesit bağımlılığı, heterojenlik ve içselliği dikkate alan ikinci nesil panel tahmin edicilerini kullanmasıdır. Eğim katsayısının heterojenliği ve yatay kesit bağımlılığı verilerin önemli bir kısmında bulunduğu için, uygulanan bu yöntemlerle güçlü, güvenilir ve sapmasız sonuçlar elde etmek mümkün olmaktadır. 
Üçüncü olarak, kamu borcuyla büyüme ilişkisi gelişmiş ve gelişmekte olan toplam 43 ülke için analiz edilmektedir. Hem tüm ülkeler için, hem de gelişmiş ve gelişmekte olan ülkeler için ayrı ayrı tahminler yapılmakta, ilişkinin ülke gruplarına göre değişip değişmediği tespit edilmektedir.

Çalışmanın geri kalanı şu şekildedir. İkinci bölümde konuya ilişkin literatür ayrıntılı bir biçimde sunulmaktadır. Üçüncü bölüm ampirik metodoloji ve veri setini açıklamaktadır. Dördüncü bölümde modele ilişkin sonuçlar raporlanırken, beşinci ve son bölüm ise sonuç ve politika önerilerinden oluşmaktadır.

\section{Literatür Taraması}

Geleneksel yaygın görüş borcun kısa vadede toplam talebi artırabileceği, uzun vadede ise özel yatırımları dışlayarak büyümeyi olumsuz yönde etkileyeceği şeklindedir (Elmendorf ve Mankiw, 1999). Standart örtüşen nesiller modelinde kamu borcu daha yüksek faizler kanalıyla tasarruf ve sermaye birikimini azaltarak ekonomik büyümeyi düşürmektedir (Modigliani, 1961; Diamond, 1965). İçsel büyüme modellerinde kamu borcunun uzun dönemli büyüme üzerindeki genellikle negatif bir etkisi bulunmaktadır (Barro, 1990).

Kamu borcunun büyüme üzerindeki olumsuz etkisi birçok farklı kanaldan gerçekleşmektedir. Kamu borcunun gelecekte kamu harcamalarının azaltılıp vergilerin artırılmasıyla ödenmesi gerekeceği, bu nedenle büyüme üzerinde olumsuz etkisinin olacağını söylemek mümkündür. Bu argümanla tutarlı olarak, Bohn (1998) ve Lo ve Rogoff (2015) hükümetlerin artan borç karşısında faiz dışı fazlayı artırma veya daha düşük bütçe açığı verme yoluna gittiklerini göstermişlerdir. Yüksek borç stoku üretken kamu yatırımlarını sınırlamakta (Teles ve Mussolini, 2014), uzun dönemli faizi yükseltip şirketlerin borçlanma maliyetlerini yükseltmekte (Gale ve Orszag, 2003; Baldacci ve Kumar, 2010), belirsizlik yaratmakta ve geleceği yönelik beklentileri kötüleştirmekte (Cochrane, 2011), risk priminin artmasına neden olmakta (Codogno vd., 2003), gelecekte kamu altyapı harcamalarının daha düşük olmasına neden olmakta (Aizenman vd. 2007), daha yüksek enflasyon yaratmakta (Sargent ve Wallace, 1981), daha yükssek reel faiz ve düşük özel yatırımlara yol açmaktadır (Laubach, 2009). Diğer taraftan, Delong ve Summers (2012) kamunun daha fazla borçlanmasına neden olan genişleyici maliye politikasının resesyondan çıkmak ve ekonomiyi canlandırmak için olumlu olduğunu belirtmiştir. Aschauer (2000) belirli bir düzeye kadar üretken sermayenin finansmanında kullanılması şartıyla borcun büyümeyi olumlu yönde etkileyebileceğini ortaya koymuştur.

Kamu borcunun ekonomik büyüme üzerindeki etkisini analiz eden geniş bir literatür bulunmaktadır. Bu alandaki daha eski çalışmaların büyük çoğunluğu dış borçla büyüme 
arasındaki ilişkiyi incelemektedir. Dış borçla büyüme arasındaki negatif ilişki yaygın olarak borç yükü hipotezine dayanmaktadır. Buna göre, ülkelerin dış borcu artınca yatırımcılar bunu finanse etmek için gelecekte daha yüksek vergilerin olacağını beklemekte, bu da yatırımları azaltıp büyümeyi düşürmektedir. Krugman (1988), Geiger (1990), Cunningham (1993) ve Deshpande (1997) bu kapsamda yapılan ve dış borçla büyüme arasında negatif bir ilişki olduğunu gösteren çalışmalar arasında yer almaktadır. Dış borç-büyüme ilişkisine yönelik diğer çalışmalardan Patillo vd. (2002) gelişmekte olan 93 ülkeyi kullanarak dış borçla büyüme arasındaki doğrusal olmayan ilişkiyi incelemiştir. Model sonuçlarına göre ortalama borçluluğa sahip bir ülkede borç oranının iki katına çıkması kişi başına büyümeyi yarım ila 1 yüzde puan düşürmektedir. Dış borcun milli gelire oranı yüzde 35-40 seviyesini geçtiğinde ilişki negatif olmaktadır. Schclarek (2004) gelişmekte olan ülkeler için düşük dış borcun daha yüksek büyümeye işaret ettiğini bulmuştur. Çalışmada, gelişmiş ülkeler için kamu diş borcuyla büyüme arasında anlamlı bir ilişki bulunmazken, dış borçla büyüme arasında ters-U şeklinde de bir ilişkinin olmadığı ortaya koyulmuştur. Guei (2019) panel ARDL modeli kulanarak gelişmekte olan ülkeler için dış borçla büyüme arasındaki ilişkiyi analiz etmiştir. Model sonuşlarına göre kısa vadede dış borçla büyüme ilişkisi negatif bulunurken, uzun vadede anlamlı bir ilişki söz konusu değildir.

Literatürdeki çalışmaların bir bölümü kamu borcuyla büyüme arasında doğrusal olmayan bir ilişki olduğuna ve belirli bir eşikten sonra ilişkinin değiştiğine işaret etmektedir. $\mathrm{Bu}$ çalışmalar arasında en çok bilinenlerden biri olan Reinhart ve Rogoff (2010) kamu borcunun milli gelire oranı yüzde 90'ın altında olduğunda iki değişken arasında ilişki bulunmadığını, kamu borcunun milli gelire oranı yüzde 90 seviyesini aştığında ise negatif bir ilişki olduğunu tespit etmiştir. Cecchetti vd. (2011) de benzer şekilde 18 OECD ülkesi kullanarak kamu borcunun milli gelire oranı yüzde 85 seviyesini geçtiğinde ilişkinin negatif olduğunu bulmuştur. Checherita ve Rother (2012) Avro Bölgesi ülkeleri için büyüme ve kamu borcu arasında doğrusal olmayan bir ilişki bulunduğunu, kamu borcunun milli gelire oranı yüzde 90 100 seviyesini geçtiğinde borcun büyümeyi olumsuz yönde etkilemeye başladığını göstermiştir. Baum vd. (2013) 12 Avro Bölgesi üyesi ülkeyle dinamik panel eşik değer metodolojisini kullarak büyümeyle kamu borcu arasındaki doğrusal olmayan ilişkiyi analiz etmiştir. Model sonuçlarına göre ekonomik büyümeyle kamu borcu arasındaki ilişki kısa dönemde pozitif olarak bulunurken, kamu borcunun milli gelire oranı yüzde 67 seviyesine ulaştığında bu ilişki kaybolmaktadır. Kamu borcunun milli gelire oranı yüzde 95 seviyesini aştığında ise ilişki negatif olmaktadır. Gómez-Puig ve Sosvilla-Rivero (2017) zaman serisi analizi kullarak Avrupa ülkeleri için kamu borcuyla büyüme arasındaki ilişkiyi incelemiş, 
kamu borcu belli bir seviyeyi geçtiğinde büyüme üzerinde olumsuz etkileri olduğunu ve oranın ülkelere göre farklılık gösterdiğini bulmuştur.

Panizza ve Presbitero (2013) ile birlikte kamu borcunun büyüme üzerindeki heterojen etkilerini analiz eden çalışmalar literatüre katılmıştır. Mitze ve Matz (2015), ülkeler arası ampirik birinci nesil çalışmaların kamu borcuyla büyüme arasında ters-U şeklinde bir ilişkinin varlığını ve özellikle yüksek borçluluk oranlarında ilişkinin negatif olarak bulduğunu belirtmiştir. Diğer taraftan, daha yeni olan ikinci nesil ampirik çalışmaların bu sonuçların sorgulanmasına neden olduğunu ifade etmiştir. Bu çalışmalar genel olarak kamu borcuyla büyüme arasındaki ilişkinin ülkelerin ekonomik, finansal, mali, teknolojik ve kurumsal farklılıklarına göre değiştiğini ortaya koymaktadır. Ülkelerin yüksek borcu tolere etme kapasitesi ülkelere özgü makro ve kurumsal yapıya bağlı olarak değişmektedir (Reinhart vd., 2003). Eberhardt ve Presbitero (2015), 118 gelişmiş ve gelişmekte olan ülkeyi kullanarak uzun dönemde kamu borcuyla büyüme arasında doğrusal olmayan negatif bir ilişkinin bulunduğunu, bununla birlikte diğer çalışmalardaki gibi kesin bir eşik değerin bulunmadığını, söz konusu ilişkinin ülkelere göre farklılık gösterdiğini bulmuştur. Egert (2015) yüzde 90 eşik değerinin sihirli bir rakam olmadığını, bunun daha düşük olabileceğini ve ülkelere göre doğrusal olmayan ilişskinin değişebileceğini ortaya koymuştur. Chudik vd. (2017) dinamik heterojen panel veri modeli kullarak gelişmiş ve gelişmekte olan 40 ülkeyi analize dahil ederek ekonomik büyüme ile kamu borcu arasında negatif bir ilişkinin var olduğunu, bununla birlikte ilişskiye yönelik genel bir eşik değerin olmadığını bulmuştur. Asteriou vd. (2020) seçilmiş Asya ülkeleri için farklı heterojen panel yöntemler kullanarak kamu borcu büyüme ilişkisini incelemiştir. Model sonuçlarına göre, hem kısa hem de uzun vadede negatif bir ilişkinin varlığı ortaya koyulmuştur.

\section{Ampirik Yöntem ve Veri Seti}

Yaygın olarak kullanılan anaakım ekonometri literatürü eğim katsayısının homojen olduğunu ve yatay kesitlerin bağımsızlığını varsaymaktadır. Ampirik çalışmaların birçoğunda sabit ve rassal etkiler modelleri, Arellano ve Bond (1991) ile Arellano ve Bover (1995) tarafindan geliştirilen genelleştirilmiş momentler yöntemi (GMM) kullanılmaktadır. Bu tahmin ediciler yatay kesit bağımlılı̆̆ını ihmal etmekte, yatay kesitler arasında sadece sabit katsayının değiştiğini ve eğim katsayısının aynı olduğunu varsaymaktadır. Eğim katsayısının heterojenliği ve yatay kesit bağımlılı̆̆ durumunda söz konusu tahminciler yanıltıcı çıkarımlara, tutarsız ve sapmalı sonuçlara neden olabilmektedir.

Panel veri ekonometrisindeki önemli bir gelişme eğim katsayısının heterojenliğini dikkate alan ve birinci nesil olarak adlandırılan tahmincilerin ortaya atılması olmuştur. $\mathrm{Bu}$ 
tahmincilerin arasında Ortalama Grup (Pesaran ve Smith, 1995), Havuzlanmış Ortalama Grup (Pesaran vd., 1999) ve Tam Değiştirilmiş EKK (Pedroni, 2000) yer almaktadır. Bu tahmin ediciler eğim katsayısının heterojenliğini dikkate alırken, yatay kesit bağımlılığının varlığ1 durumunda tutarsiz tahminler vermektedir.

Yatay kesit bağımlılığı panel zaman serileri literatürüne nispeten yeni eklenmiş bir konu olmakla birlikte makroekonomik ve finansal verilerde yatay kesit bağımlılığının oldukça yaygın bir biçimde gözlendiğini söylemek mümkündür. Yatay kesit bağımlığı finansal krizler, emtia fiyat dalgalanmaları ve virüs salgını gibi ortak küresel şoklar yada Çin'in dünyadaki yükselişi ve yeni teknolojiler gibi eğilimlerin etkisiyle ortaya çıkmaktadır. Günümüzün küreselleşen dünyasında ülkeler arasındaki ilişkilerin giderek güçlenmesi yatay kesit bağımlılığını dikkate almayı gerektirmektedir. Yatay kesit bağımlılığının görmezden gelinmesinin yanlış tahmin ve belirleme sorunları gibi birçok olumsuz sonuçları olabilmektedir. Bu nedenle, hem heterojenliği hem de yatay kesit bağımlılığını dikkate alan tahmin edicilerin ortaya atılması panel zaman serileri literatürü açısından oldukça önemli olmuştur. İkinci nesil olarak da adlandırılan bu tahmin ediciler arasında Ortak İlişkili Etkiler (Pesaran, 2006) ve Genişletilmiş Ortalama Grup (Eberhardt and Bond, 2009) tahmin edicileri yer almaktadir.

Bu çalışma, büyüme ile kamu borcu arasındaki ilişkiyi analiz etmek amacıyla hem eğim katsayısının heterojenliğini hem de yatay kesit bağımlılığının varlığını dikkate alan yukarıda sözü edilen tahmin edicileri kullanmaktadır.

Ortak İlişkili Etkiler (CCE) tahmin edicisi ilk olarak Pesaran (2006) tarafından ortaya atılmış, sonrasında Kapetanios vd. (2011) tarafından geliştirilmiştir. Bu tahmin edici eğim katsayısının heterojenliği ve yatay kesit bağımlılı̆̆ına ilave olarak, yapısal kırılmalar ve durağan olmayan gözlemlenmeyen ortak etkilere karşı da güçlüdür. CCE tahmin edicisi tahmin metodolojisi şu şekildedir:

$$
y_{i t}=\alpha_{1 i}+\beta_{i} x_{i t}+\varphi_{i} f_{t}+\varepsilon_{i t}
$$

Yukarıdaki denklemde $x_{i t}$ ve $y_{i t}$ gözlemleri, $\beta_{i}$ ülkelere özgü eğim katsayısını, $\alpha_{1 i}$ ülkeler arasında zamandan bağımsız var olan heterojenliği kapsayan sabit grup etkilerini, $\mathrm{f}_{\mathrm{t}}$ gözlemlenmeyen ortak heterojen faktörleri ve cit hata terimini göstermektedir. (1) numaralı denklem bağımlı ve bağımsız değişkenlerin yatay kesit ortalamaları ile aşağıdaki gibi genişletilmektedir.

$$
y_{i t}=\alpha_{1 i}+\beta_{i} x_{i t}+\delta_{i} \bar{y}_{i t}+\theta_{i} \bar{x}_{i t}+\varphi_{i} f_{t}+\varepsilon_{i t}
$$

Daha sonra denklem her yatay kesit için EKK ile tahmin edilmektedir. 
Heterojen eğim katsayıları durumunda, bütün panele ilişkin çıkarım yapmak için ortalama grup tahmin edicisi kullanılabilmektedir. CCE için ortalama grup tahmin edicisi her bir yatay kesite ait katsayıların aritmetik ortalaması alınarak aşağıdaki gibi hesaplanır.

$$
\text { CCEMG }=N^{-1} \sum_{i=1}^{N} \hat{\beta}_{i}
$$

Yukarıdaki denklemde $\hat{\beta}_{i}$ (2) nolu denklemdeki katsayıların tahminlerini göstermektedir.

Çalışmamızda kullanılan ikinci tahmin edici Eberhardt ve Bond (2009) ile Eberhardt ve Teal (2010) tarafından geliştirilen geniş̧letilmiş ortalama grup (AMG) tahmin edicisidir. $\mathrm{Bu}$ tahmin edici de CCE gibi eğim katsayısının heterojenliği ve yatay kesit bağımlılığına karşı güçlüdür. İki tahmin edici arasındaki temel fark (1) nolu denklemdeki $\mathrm{f}_{t}$ ortak faktörüne ilişkin kestirim yöntemidir. CCE tahmin edicisi bağımlı ve bağımsız değişken ile ortak etkilerin yatay kesit ortalamalarının lineer kombinasyonlarını kullanmaktadır. Daha sonra, her bireysel katsayı EKK ile tahmin edilmektedir (Kapetanios vd., 2011). AMG tahmin edicisinde ise, gözlemlenmeyen dinamik ortak etkilerin tahmin edilmesinde iki aşamalı bir yöntem uygulanmakta ve ortak dinamik etkiler parametresinin dahil edilmesiyle yatay kesit bağımlılığı dikkate alınmaktadır.

Öncelikle, denklem zaman kuklasıyla genişletilmekte ve birinci fark EKK ile aşağıdaki gibi tahmin yapılmaktadır.

$$
\Delta y_{i t}=\alpha_{1 i}+\beta_{i} \Delta x_{i t}+\varphi_{i} f_{t}+\sum_{t=2}^{T} \tau_{t} D U M M Y_{t}+\varepsilon_{i t}
$$

$\mathrm{Bu}$ tahminle zaman kuklalarının katsayıları elde edilirken, buna ortak dinamik süreç denmektedir (Eberhardt, 2012). Daha sonra, grup spesifik regresyon modeli açık değişken veya her grup üyesine birim katsayı empoze edilerek genişletilmektedir. Birim katsayının empoze edilmesi bağımlı değişkenden AMG tahmin edicisinin çıkarılmasıyla yapılmaktadır. CCE tahmin edicisine benzer şekilde, grup spesifik model parametrelerinin panel boyunca ortalaması alınmaktadır. Her regresyon zamandan bağımsız sabit etkileri kapsayan bir kesme noktasını içermektedir. AMG için ortalama grup tahmin edicisi CCE tahmin edicisindeki gibi elde edilmektedir.

$$
A M G=N^{-1} \sum_{i=1}^{N} \tilde{\beta}_{i}
$$

Yukarıdaki denklemde $\tilde{\beta}_{i}$ (4) numaralı denklemdeki katsayıların tahminini göstermektedir.

Çalışmamızda büyüme oranı ile kamu borcu arasındaki ilişki ortak ilişkili etkiler (CCE) ve genişletilmiş ortalama grup (AMG) tahmin edicileri kullanılarak analiz edilmektedir. Modelde bağımlı değişken olarak yıllık GSYİH büyüme oranı kullanılmaktadır. Açıklayıcı değişkenlerden birisi genel hükümet borcunun GSYİH'ye oranıdır. Modelimizdeki kontrol değişkenleri standart ampirik büyüme literatürüne paralel olarak seçilmiştir (Sala-i-Martin (1997), Barro ve Sala-i-Martin (2004)). Ekonomik büyüme literatüründe, üretim sürecinde 
kullanılan işgücünün büyüme oranı ve fiziksel sermaye birikimi (yatırım) büyümenin temel belirleyicileri arasında yer almaktadır (Solow (1956), Frankel (1962)). Bu nedenle nüfus artıș1 ve brüt sabit sermaye oluşumunun GSYİH'ye oranı, işgücünün büyümesi ve fiziksel sermaye birikimi için vekil olarak kullanılmaktadır. Nüfus artışı ve ekonomik büyüme ilişskisine yönelik literatürde farklı sonuçlar bulunmaktadır. Levine ve Renelt (1992) bu ilişkinin negatif ve anlamsız olduğunu, Mankiw vd. (1992) negatif ve anlamlı olduğunu, Sachs ve Warner (1997) ise pozitif ve anlamlı olduğunu bulmuşlardır. Literatürdeki çalışmaların büyük çoğunluğu ekonomik büyüme ile fiziksel sermaye stoku arasında pozitif ve anlamlı bir ilişki olduğunu ortaya koymaktadır. Hükümetin tüketim harcamalarının GSYİH’ye oranı maliye politikasının bir göstergesi olarak modele dahil edilmektedir. Hükümetin tüketim harcamalarının artması bir taraftan talebi artırarak büyümeyi pozitif yönde etkilemektedir. Diğer taraftan, birçok ampirik çalışma hükümet harcamalarının büyümeyi olumsuz yönde etkilediğini göstermektedir. (Barro (1990), King ve Rebelo, (1990)). Hükümet tüketimindeki artış özel sektörün yatırımlarını dışlayarak ve çarpık vergilendirmeyi teşvik ederek büyümeyi azaltabilmektedir (Akinlo, 2004). İhracat ve ithalat toplamının GSYİH'ye oranı ülkenin dışa açıklığının bir göstergesi olarak ve uluslararası ekonomik gelişmelerin etkisini göstermesi açısından kullanılmaktadır. Dışa açıklık ekonomik büyümenin önemli bir belirleyici olarak kabul edilmektedir (Frankel ve Romer, 1999). Dışa açıklık bilgi transferleri ve verimlilik kazanımlarıyla üretkenliği artırmaktadır (Seghezza ve Baldwin (2008)). Romer (1992), Barro ve Sala-i-Martin (1995) ve Edwards (1998) büyüme ile dışa açıklık arasında pozitif ilişki olduğunu göstermektedir. Mangır vd. (2017) da panel ARDL yöntemi kularak 10 Afrika ülkesi için dışa açıklıkla büyüme arasında uzub vadeli pozitif bir ilişki olduğu sonucuna ulaşmıştır. Yıılık enflasyon oranı uygulanan makroekonomik politikaların ve ekonomik istikrarın bir göstergesi olarak modele eklenmektedir. Enflasyon hükümetin ekonomiyi nasıl yönettiğine ilişkin bir gösterge olarak yorumlanabilmektedir (Barro (2003)). Düşük enflasyon, fiyat mekanizması yoluyla kıt kaynakların en iyi yerlerde kullanılmasını sağlayıp ekonomik etkinliği artırmaktadır. Bu nedenle, büyüme ile enflasyon arasında genellikle negatif bir ilişkinin olduğu kabul edilmektedir.

Bu çalışma, 1960-2018 dönemini içeren y1llık verilerle 23'ü gelişmiş, 20'si gelişmekte olan 43 ülkeyi kapsamaktadır. Çalışmaya dahil edilen gelişmiş ülkeler Avustralya, Avusturya, Kanada, Danimarka, Finlandiya, Fransa, Almanya, Yunanistan, İzlanda, İrlanda, İtalya, Japonya, Güney Kore, Hollanda, Yeni Zelanda, Norveç, Portekiz, Singapur, İspanya, İsveç, İsviçre, İngiltere ve ABD’dir. Çalışmadaki gelişmekte olan ülkeler ise Kamerun, Şili, Çin, Kongo, El Salvador, Guatemala, Honduras, Hindistan, Endonezya, Kenya, Malezya, Meksika, 
Fas, Paraguay, Senegal, Güney Afrika, Tayland, Togo, Türkiye ve Uruguay olarak sıralanmaktadır. Veri kısıtı altında mümkün olduğunca çok sayıdaki ülke çalışmaya dahil edilmiştir. Büyüme oranı, kamu tüketim harcamalarının milli gelire oranı, sabit sermaye yatırımlarının milli gelire oranı, enflasyon oranı, yıllık nüfus artış hızı ve dış ticaretin milli gelire oranına ilişkin veriler Dünya Bankası'nın dünya kalkınma göstergeleri veritabanından alınırken, kamu borç stokunun milli gelirine oranına ilişkin veriler ise Uluslararası Para Fonu (IMF) veritabanından temin edilmiştir.

Model tahminine geçmeden önce, kullanılan serilerin özet istatistikleri Tablo 1'de sunulmuştur.

Tablo 1. Özet İstatistikler

\begin{tabular}{|l|c|c|c|c|c|}
\hline & $\begin{array}{l}\text { Veri } \\
\text { Sayısı }\end{array}$ & Ortalama & $\begin{array}{l}\text { Std. } \\
\text { Sapma }\end{array}$ & Min & Max \\
\hline Büyüme Oranı & 2.501 & 3,83 & 3,89 & -27.27 & 25.16 \\
\hline Kamu Harcamaları/GSYIH & 2.401 & 15,31 & 4,88 & 2,98 & 27,94 \\
\hline Dış Ticaret/GSYİH & 2.428 & 66,09 & 53,12 & 4,92 & 437,33 \\
\hline Enflasyon Oranı & 2.435 & 9,19 & 31,09 & $-7,63$ & 1136,25 \\
\hline Sabit Sermaye Yatırımlarl/GSYİH & 2.355 & 22,89 & 6,34 & 3,40 & 95,32 \\
\hline Nüfus Artış Hızı & 1.950 & 3,01 & 1,05 & 1,50 & 5,11 \\
\hline Kamu BorçStoku/GSYİH & 1.950 & 2,15 & 0,14 & 1,78 & 2,40 \\
\hline
\end{tabular}

Kaynak: Yazar Hesaplamalart

Özet istatistiklerden sonra, serilerin panel veri özellikleri incelenmiştir. Bu çerçevede, öncelikle serilerin duralanlığg test edilmiş, sonrasından da yatay kesit bağımlılığı analiz edilmiştir.

Kullanılan serilerin duralanlığının test edilmesi ampirik çalışmalarda artık standart haline gelmiştir. Çalışmamızda serilerin durağanlık özellikleri gerek yatay kesit bağımlılığını dikkate almayan birinci nesil Maddala ve Wu (1999) testi, gerekse de yatay kesit bağımlılığını dikkate alan ikinci nesil Pesaran (2007) CIPS testiyle yapılmıştır. İki testte de sıfır hipotezi birim kökün varlığını göstermektedir. Test sonuçları aşağıda Tablo 2'de sunulmaktadır. Test sonuçlarına göre dış ticaretin milli gelire oranı haricindeki seriler düzey hallerinde durağan iken (I(0)), diş ticaret göstergesinin birinci farkı durağandır (I(1)). Bu nedenle, modelde bu serinin birinci farkı kullanılmıştır.

Tablo 2. Panel Birim Kök Test Sonuçları

\begin{tabular}{|l|l|l|l|c|}
\hline \multirow{2}{*}{} & \multicolumn{3}{|l|}{ Madalla and Wu Testi } & \multicolumn{2}{l|}{ Paseran CIPS Testi } \\
\cline { 2 - 5 } & Düzey & Birinci Fark & Düzey & Birinci Fark \\
\hline Büyüme Oranı & $960,6 * * *$ & $2.234,2 * * *$ & $-15,16^{* * * *}$ & $-29.10^{* * *}$ \\
\hline
\end{tabular}




\begin{tabular}{|c|c|c|c|c|}
\hline Kamu Harcamalarl/GSYIHH & $145,2 * * *$ & $967,2 * * *$ & $-1,85 * *$ & $-18,50 * * *$ \\
\hline Diş Ticaret/GSYİH & $72,9 * * *$ & $1.153,0 * * *$ & $-1,06$ & $-19,69 * * *$ \\
\hline Enflasyon Oranı & $297,9 * * *$ & $1.676,2 * * *$ & $-10,99 * * *$ & $-27,21 * * *$ \\
\hline Sabit Sermaye Yatırımlarl/GSYİH & $201,2 * * *$ & $963,4 * * *$ & $-4,47 * * *$ & $-20,56 * * *$ \\
\hline Nüfus Artış Hızı & $382,8 * * *$ & $1.417,5^{* * *}$ & $-11,55 * * *$ & $-21,92 * * *$ \\
\hline Kamu Borç Stoku/GSYİH & $215,4 * * *$ & $1074,0 * * *$ & $-5,75 * * *$ & $-21,36 * * *$ \\
\hline
\end{tabular}

Kaynak: Yazar Hesaplamaları

Ekonomik krizler, salgınlar ve petrol fiyat değişimleri gibi tüm ülkeleri etkileyen ortak şoklar ile küreselleşme nedeniyle ülkelerin ekonomik göstergeleri arasında güçlü ilişki ve bağımlılık bulunmaktadır. Tüm bu nedenlerden dolayı, makroekonomik verilerde yatay kesit bağımlılığı günümüzde artık istisnadan ziyade genel bir kural haline gelmeye başlamıştır. Bu bağlamda, ampirik çalışmalarda kullanılan serilerin yatay kesit bağımlılığını test etmek daha da önemli hale gelmiştir. Yatay kesit bağımlılığının varlığı durumunda ikinci nesil tahmin edicilerin kullanılması gerekmektedir. Çalışmamızda, yatay kesit bağımlılığını test etmek amacıyla Pesaran (2004) tarafından geliştirilen CD testi kullanılmaktadır. Test sonuçları Tablo 3'te gösterilmektedir. Buna göre, kullanılan tüm seriler için yatay kesit bağımsızlığı sıfır hipotezi yüzde 1 anlamlılık düzeyinde reddedilmektedir. Serilerimizde yatay kesit bağımlılı̆̆ bulunmaktadır.

Tablo 3. Yatay Kesit Bağımlılığı Test Sonucu

\begin{tabular}{|l|c|}
\hline & CD Testi \\
\hline Büyüme Oranı & $40,12 * * *$ \\
\hline Kamu Harcamaları/GSYİH & $41,50 * * *$ \\
\hline Dış Ticaret/GSYİH & $105,71 * * *$ \\
\hline Enflasyon Oranı & $94,56 * * *$ \\
\hline Sabit Sermaye Yatırımları/GSYİH & $13,68 * * *$ \\
\hline Nüfus Artış Hızı & $34,77 * * *$ \\
\hline Kamu BorçStoku/GSYİH & $18,67 * * *$ \\
\hline
\end{tabular}

*, **, *** siraslyla \% 10, \% 5 ve \% 1 düzeyinde istatistiksel olarak anlamlılığ göstermektedir. Sifır hipotezi yatay kesit bağımlılı̆̆ının olmadı̆̆ını göstermektedir.

Kaynak: Yazar Hesaplamalarl

Çalışmamızda kullanılan serilerde yatay kesit bağımlılığının varlığı nedeniyle, ikinci nesil tahmin ediciler olan Ortak İlişkili Etkiler ve Genişletilmiş Ortalama Grup tahmin edicileri kullanılacaktır. 


\section{Ampirik Sonuçlar}

Ortak İlişkili Etkiler (CCE) ve Genişletilmiş Ortalama Grup (AMG) tahmin sonuçları Tablo 4'te sunulmaktadır. İlk 2 sütünda, paneldeki tüm ülkeler kullanılarak tahminler oluşturulmuştur. Sonraki 2 sütünda sadece gelişmiş ülkeler, son 2 sütunda ise sadece gelişmekte olan ülkeler kullanılarak bulunan model sonuçları gösterilmektedir. Böylece, model sonuçlarının ülke gruplarına göre değişip değişmediği analiz edilmiştir.

Tablo 4. Model Sonuçları

\begin{tabular}{|c|c|c|c|c|c|c|}
\hline $\begin{array}{l}\text { Açılklayıcı } \\
\text { Değişkenler }\end{array}$ & CCE-Tüm & AMG-Tüm & $C C E-G \ddot{U}$ & $A M G-G \ddot{U}$ & $\begin{array}{l}C C E- \\
G O \ddot{U} \\
\end{array}$ & $\begin{array}{l}A M G- \\
G O \ddot{U}\end{array}$ \\
\hline $\begin{array}{l}\text { Kamu } \\
\text { Harcamast }\end{array}$ & $\begin{array}{c}-0,825^{* * *} \\
(-8,46)\end{array}$ & $\begin{array}{c}-0,628 * * * \\
(-8,84)\end{array}$ & $\begin{array}{c}-0,787 * * * \\
(-5,58)\end{array}$ & $\begin{array}{c}-0,879 * * * \\
(-7,52)\end{array}$ & $\begin{array}{c}-0,649 * * * \\
(-4,97)\end{array}$ & $\begin{array}{c}-0,611 \text { *** } \\
(-5,48)\end{array}$ \\
\hline $\begin{array}{l}\text { Dışa } \\
\text { Açıklık }\end{array}$ & $\begin{array}{l}-0,002 \\
(-0,06) \\
\end{array}$ & $\begin{array}{l}0,027 \\
(1,09) \\
\end{array}$ & $\begin{array}{l}0,021 \\
(0,77) \\
\end{array}$ & $\begin{array}{c}0.103 * * * \\
(3,27) \\
\end{array}$ & $\begin{array}{l}-0,033 \\
(-0,83) \\
\end{array}$ & $\begin{array}{l}-0,026 \\
(-0,88) \\
\end{array}$ \\
\hline Enflasyon & $\begin{array}{c}-0,120 * * * \\
(-3,19)\end{array}$ & $\begin{array}{c}-0,122 * * * \\
(-3,79)\end{array}$ & $\begin{array}{c}-0,201 * * * \\
(-4,31) \\
\end{array}$ & $\begin{array}{c}-0.231 * * * \\
(-4,85) \\
\end{array}$ & $\begin{array}{l}-0.030 \\
(-0,77) \\
\end{array}$ & $\begin{array}{l}-0,032 \\
(-0,99) \\
\end{array}$ \\
\hline Yatırım & $\begin{array}{c}0,198 * * * \\
(4,07)\end{array}$ & $\begin{array}{c}0,174 * * * \\
(4,29)\end{array}$ & $\begin{array}{c}-0,139 * * \\
(2,53)\end{array}$ & $\begin{array}{c}0,175^{* * *} * \\
(2,59)\end{array}$ & $\begin{array}{c}0,179 * * \\
(2,48)\end{array}$ & $\begin{array}{c}0,252^{* * * *} \\
(3,68)\end{array}$ \\
\hline Nüfus Artışı & $\begin{array}{c}-1,01 \\
(-1,56) \\
\end{array}$ & $\begin{array}{r}0,247 \\
(0,86) \\
\end{array}$ & $\begin{array}{l}0,198 \\
(0,44) \\
\end{array}$ & $\begin{array}{l}0,285 \\
(0,82) \\
\end{array}$ & $\begin{array}{l}-0,551 \\
(-0,37) \\
\end{array}$ & $\begin{array}{c}-1,04 \\
(-1,19) \\
\end{array}$ \\
\hline $\begin{array}{l}\text { Кати } \\
\text { Вогси }\end{array}$ & $\begin{array}{c}0,0001 \\
(0,51)\end{array}$ & $\begin{array}{c}-0,0001 \\
(-0,38)\end{array}$ & $\begin{array}{l}0,006^{*} \\
(1,85)\end{array}$ & $\begin{array}{c}0.0006^{* *} \\
(1,99)\end{array}$ & $\begin{array}{c}-0,002 * * \\
(-2,04)\end{array}$ & $\begin{array}{c}-0,012 * \\
(-1,68)\end{array}$ \\
\hline
\end{tabular}

Not: Bă̆ımlı değişken: GSYIHH büyüme oranı. İlgili t istatistiği parantez içinde sunulmuştur. *, **, *** sirasiyla \% 10, \% 5 ve \% 1 düzeyinde istatistiksel olarak anlamlllı̆̆ ifade etmektedir.

\section{Kaynak: Yazar Hesaplamalar}

Çalışmamızda, gerek tüm ülkeler modele dahil edildiğinde, gerekse gelişmiş ve gelişmekte olan ülkelere ayrı ayrı bakıldığında kamu tüketim harcamaları ile ekonomik büyüme arasında negatif ve yüzde 1 düzeyinde istatistiksel olarak anlamlı bir ilişki olduğu görülmektedir. Kamu tüketim harcamalarının milli gelire oranı arttıkça büyüme oranı düşmektedir. Literatürde de benzer sonuçlara ulaşan çalışmalar bulunmaktadır (Barro (1990), King ve Rebelo, (1990)). Kamu tüketimindeki artış etkinliği azaltarak ve özel sektör yatırımlarını dışlayarak büyümeyi olumsuz yönde etkileyebilmektedir. Model sonuçları ekonominin dışa açıklığı ile büyüme arasında anlamlı bir ilişkiye işaret etmemektedir. Sadece gelişmiş ülke verileriyle Genişletilmiş Ortalama Grup (AMG) tahmin edicisi kullanıldığında pozitif ve anlamlı bir ilişki bulunmuştur. Enflasyon ve büyüme arasında literatüre paralel olarak negatif ve anlamlı bir ilişki olduğu sonucuna ulaşılmıştır. Enflasyondaki artış ekonomide istikrarsızlık yaratarak, yatırım ve tasarrufları olumsuz yönde etkileyerek ve üretim faktörlerinin etkin dağılımını engelleyerek büyümeyi düşürmektedir. Tüm ülkeler ve 
gelişmiş ülkeler modele dahil edildiğinde enflasyonla büyüme arasında negatif ve istatistiksel olarak anlamlı bir ilişki bulunurken, gelişmekte olan ülkeler için katsayı negatif olmakla birlikte anlamlı değildir. Sabit sermaye oluşumunun (yatırımlar) milli gelire oranı ile büyüme oranı arasında ampirik literatürde de bulunduğu üzere pozitif ve anlamlı bir ilişki olduğu gözlenmektedir. Yatırımların milli gelire oranı arttıkça ekonomik aktivite de olumlu yönde etkilenmektedir. Sabit sermaye stokundaki artış işgücünün verimliliğini artırmakta, toplam talebi yükselterek büyüme oranını pozitif yönde etkilemektedir. Modelimizde nüfus artışı ile ekonomik büyüme arasında anlamlı bir ilişki bulunamamıştır. Kamu borç stoku ile büyüme arasındaki ilişki tüm ülkeler modele katıldığında anlamsız çıkmaktadır. Diğer taraftan, gelişmiş ve gelişmekte olan ülkelere ayrı ayrı bakıldığında farklı sonuçlara ulaşılmaktadır. Gelişmiş ülkelerde, kamu borç stoku ile büyüme oranı arasında pozitif bir ilişki bulunurken, gelişmekte olan ülkelerde tam tersi negatif bir ilişki tespit edilmiştir. Gelişmekte olan ülkelerin gelişmiş ülkelere kıyasla borçlanma imkanlarının daha kısıtlı olması, risk priminin daha yüksek olması, daha yüksek faiz oranına bağlı olarak borç servisinin daha fazla olması ve yüksek kamu borcunun gerek kamunun gerekse özel sektörün yatırımlarını dışlaması bu farkı açıklayabilecek faktörlerden bazılarıdır.

\section{Sonuç}

2019 yılı sonlarında Çin'de başlayıp 2020 yılının ilk aylarında tüm dünyaya yayılan Kovid-19 salgını nedeniyle ülkeler genişletici maliye politikası uygulamaya başlamış, bütçe açığı artış göstermiş, dünyada kamu borç stoku tarihi yüksek seviyelere ulaşmıştır. Bu nedenle, borç stokundaki artışın ekonomik büyüme üzerindeki muhtemel etkileri tekrar gündeme gelmeye başlamış, politika yapıcıların dikkati artan ölçüde bu alana yönelmiştir. Bu çalışmanın amacı, kamu borcu-büyüme literatürüne katkı sağlamak ve politika yapıcılar için çıkarımlarda bulunmaktır.

Bu çalışma kamu borç stoku ile büyüme arasındaki ilişkiyi geniş bir veri seti kullanarak analiz etmektedir. Çalışmada, günümüzde makro panel verilerde artık neredeyse standart haline gelmiş olan yatay kesit bağımlılığı ve eğim katsayısının heterojenliğini dikkate alan, ikinci nesil olarak da ifade edilen, ortak ilişkili etkiler (CCE) ve genişletilmiş ortalama grup (AMG) tahmin edicileri kullanılmıştır. Bu tahmin edicilerle yapılan tahminler yatay kesit bağımlılığı ve katsayı heterojenliğini hesaba katmayan modellere göre daha tutarlı, sapmasız ve güçlüdür.

Çalışmamızda oluşturulan büyüme modeli sonuçlarına göre, kamu tüketim harcamaları ve enflasyonla ekonomik büyüme arasında negatif bir ilişki bulunmaktadır. Kamunun tüketim harcamaları arttıkça ve enflasyon yükseldikçe büyüme oranı düşmektedir. Sabit sermaye 
yatırımları ve büyüme arasında ise pozitif ve istatistiksel olarak anlamlı bir ilişki olduğu tespit edilmiştir. Model sonuçları büyümeyle ekonominin dışa açıklığı ve nüfus artışı hızı arasında anlamlı bir ilişki olmadığına işaret etmektedir. Diğer taraftan, kamu borç stoku ile büyüme arasındaki ilişki analize dahil edilen ülke gruplarına göre değişmektedir. Gelişmiş ülkeler için kamu borcu ve büyüme ilişkisi pozitif olarak bulunurken, gelişmekte olan ülkeler için ise negatif olarak tespit edilmiştir.

Kamu borcuyla büyüme arasındaki ilişkinin ülke gruplarına göre farklılık göstermesi ve özellikle gelişmekte olan ülkeler için negatif olması politika yapıcılar için büyük önem arz etmektedir. Gelişmiş ve gelişmekte olan ülkelerin ekonomik, mali, finansal, teknolojik ve kurumsal farklılıkları nedeniyle ülkelerin kamu borcunu tolere etme kapasiteleri arasında farklılıklar bulunmaktadır. Gelişmiş ülkeler gelişmekte olan ülkelere göre genel anlamda daha düşük faiz oranı ve risk primi, daha yüksek borçlanma kapasitesi, daha düşük borç servisi ve daha güçlü bir kurumsal yapıya sahiptir. Bu gibi nedenlerle, gelişmiş ülkelerde borç stoku artışının büyüme üzerinde olumsuz etkisi olmayabilmektedir. Diğer taraftan, model sonuçlarımızın da gösterdiği üzere gelişmekte olan ülkeler için borç stokuyla büyüme arasında negatif bir ilişki bulunmaktadır. Bu sebeple, gelişmekte olan ülkelerin kamu borç stokunun artış eğiliminde olduğu bu süreçte daha dikkatli olmaları ve kamu borç stokundaki artışı tersine çevirecek adımları atmaları gerekmektedir. Bu kapsamda, ekonomik aktivitede toparlanmanın sağlanmasıyla birlikte, borç stoku yükselen ülkelerin kredibilitesi olan orta vadeli bir mali konsolidasyon planı ortaya koymaları faydalı olabilecektir. Harcamaların daha verimli alanlara yönlendirilmesi ve gereksiz olanların kesilmesi, vergi tabanının genişletilmesi, kayıtdışılığın azaltılmasıyla ve dijitalleşmeyle vergi tahsilatının artırılması daha sürdürülebilir bir kamu maliyesi ve borç yükü için gerekli politikalar arasında yer almaktadir. 


\section{KAYNAKÇA}

Akinlo, A. Enisan. 2004. "Foreign direct investment and growth in Nigeria: An empirical investigation." Journal of Policy Modeling, 26(5) 627-639.

Aizenman, Joshua, Kenneth, Kletzer ve Brian, Pinto. 2007. "Economic growth with constraints on tax revenues and public debt: implications for fiscal policy and cross-country differences." National Bureau of Economic Research, No. 12750.

Arellano, Manuel ve Bond, Stephen. 1991. "Some tests of specification for panel data: Monte Carlo evidence and an application to employment equations." The Review of Economic Studies, 58(2), 277-297.

Arellano, Manuel ve Bover, Olympia. 1995. "Another look at the instrumental variable estimation of errorcomponents models." Journal of Econometrics, 68(1), 29-51.

Aschauer, David Alan. 2000. "Public capital and economic growth: issues of quantity, finance, and efficiency." Economic Development and Cultural Change, 48(2), 391-406.

Asteriou, Dimitrios, Keith, Pilbeam ve Cecilia Eny Pratiwi. 2020. "Public debt and economic growth: panel data evidence for Asian countries." Journal of Economics and Finance. 1-18.

Barro, Robert J. 1990. "Government spending in a simple model of endogenous growth." Journal of Political Economy, 98, S103-S125.

Barro, Robert J. 2003. "Determinants of economic growth in a panel of countries." Annals of Economics and Finance, 4, 231-274.

Barro, Robert J. ve Sala-i-Martin, Xavier. 1995. "Economic growth.” Cambridge MA: The MIT Press.

Barro, Robert J. ve Sala-i-Martin, Xavier. 2004. "Economic growth (2nd ed.)." Cambridge MA: The MIT Press.

Baum, Anja, Cristina, Checherita-Westphal ve Rother, Philipp. 2013. "Debt and growth: New evidence for the euro area." Journal of International Money and Finance, 32, 809-821.

Blundell, Richard ve Bond, Stephen. 1998. "Initial conditions and moment restrictions in dynamic panel data models." Journal of Econometrics, 87(1), 115-143.

Bohn, H. 1998. "The behavior of US public debt and deficits." The Quarterly Journal of Economics, 113(3), 949-963.

Cecchetti, S., Mohanty, M., Zampolli, F. 2011. "The real effects of debt.” Bank for International Settlements, No. 352.

Checherita-Westphal, C., Rother, P. 2012. "The impact of high government debt on economic growth and its channels: An empirical investigation for the euro area." European Economic Review, 56(7), 1392-1405.

Chudik, A., Mohaddes, K., Pesaran, M. H., Raissi, M. 2017. "Is there a debt-threshold effect on output growth?." Review of Economics and Statistics, 99(1), 135-150.

Cochrane, John H. 2011. "Understanding policy in the great recession: Some unpleasant fiscal arithmetic." European Economic Review, 55(1), 2-30.

Codogno, Lorenzo, Favero, Carlo ve Missale, Alessandro. 2003. "Yield spreads on EMU government bonds." Economic Policy, 18(37), 503-532.

Cunningham, Rosemary T. 1993. "The effects of debt burden on economic growth in heavily indebted developing nations.” Journal of Economic Development, 18(1), 115-126.

DeLong, J. Bradford ve Summers, Lawrence. 2012. "Fiscal Policy in a Depressed Economy." Brookings Papers on Economic Activity, 233-297.

Deshpande, Ashwini. 1997. "The debt overhang and the disincentive to invest." Journal of Development Economics, 52(1), 169-187.

Diamond, Peter A. 1965. "National debt in a neoclassical growth model." The American Economic Review, 55(5), 1126-1150.

Eberhardt, Markus ve Bond, Stephen. 2009. "Cross-section dependence in nonstationary panel models: a novel estimator." University Library of Munich, No. 17692, Germany.

Eberhardt, Markus ve Presbitero, Andrea F. 2015. "Public debt and growth: Heterogeneity and nonlinearity." Journal of International Economics, 97(1), 45-58.

Eberhardt, Markus ve Teal, Francis. 2010. "Productivity analysis in global manufacturing production." University of Oxford Economics Series Working Papers, 515.

Eberhardt, Markus. 2012. "Estimating panel time-series models with heterogeneous slopes." The Stata Journal, 12(1), 61-71.

Edwards, Sebastian. 1998. “Openness, productivity and growth.” Economic Journal, 108, 383-398.

Égert, Balázs. 2015. "Public debt, economic growth and nonlinear effects: Myth or reality?." Journal of Macroeconomics, 43, 226-238.

Elmendorf, Douglas W. ve Mankiw, Gregory N. 1999. "Government debt.” In: Taylor, J.B., Woodford, M. (Eds.), Handbook of Macroeconomics. Elsevier, pp. 1615-1669.

Frankel, Marvin. 1962. "The production function in allocation and growth: A synthesis." American Economic Review, 52, 996-1022. 
Frankel, Jeffrey A. ve Romer, David H. 1999. "Does trade cause growth?.” American Economic Review, 89(3), 379-399.

Gale, William G. ve Orszag, Peter R. 2003. "The economic effects of long-term fiscal discipline." UrbanBrookings Tax Policy Center Discussion Paper no. 8.

Geiger, Linwood T. 1990. "Debt and economic development in Latin America." The Journal of Developing Areas, 24(2), 181-194.

Gómez-Puig, M. ve Sosvilla-Rivero, S. 2017. "Heterogeneity in the debt-growth nexus: Evidence from EMU countries." International Review of Economics \& Finance, 51, 470-486.

Guei, K. M. 2019. "External debt and growth in emerging economies.” International Economic Journal, 33(2), 236-251.

Kapetanios, George, Pesaran, Hashem M. ve Yamagata, Takashi. 2011. "Panels with non-stationary multifactor error structures." Journal of Econometrics, 160(2), 326-348.

King, Robert G. Ve Rebelo, Sergio. 1990. "Public policy and economic growth: developing neoclassical implications." Journal of Political Economy, 98(5, Part 2), S126-S150.

Krugman, Paul. 1988. "Financing vs. forgiving a debt overhang." Journal of Development Economics, 29(3), 253-268.

Kumar, Mr Manmohan S. ve Baldacci, Emanuele. 2010. "Fiscal deficits, public debt, and sovereign bond yields.” International Monetary Fund, No. 10-184.

Im, Kyung So, Pesaran, Hashem M. ve Shin, Yongcheol. 2003. "Testing for unit roots in heterogeneous panels." Journal of Econometrics, 115(1), 53-74.

IMF. 2020. “World Economic Outlook Update: A Crisis Like No Other, An Uncertain Recovery.” International Monetary Fund, June 2020.

Laubach, Thomas. 2009. "New evidence on the interest rate effects of budget deficits and debt." Journal of the European Economic Association, 7(4), 858-885.

Levine, Ross ve Renelt, David. 1992. "A sensitivity analysis of cross-country growth regressions." American Economic Review, 82, 942-963.

Lo, Stephanie ve Rogoff, Kenneth. 2015. "Secular stagnation, debt overhang and other rationales for sluggish growth, six years on.” BIS Working Papers, 482.

Maddala, Gangadharrao S. ve Wu, Shaowen. 1999. "A comparative study of unit root tests with panel data and a new simple test." Oxford Bulletin of Economics and Statistics, 61(S1), 631-652.

Mangır, Fatih, Kabaklarlı, Esra ve Ayhan, Fatih. 2017. "An analysis for the relationship between trade openness and economic growth: evidence for ten African countries." Journal of Management and Economics Research. 15(1), 58-71.

Mankiw, Gregory N., Romer, David ve Weil, David N. 1992. "A contribution to the empirics of economic growth." Quarterly Journal of Economics, 107, 407-437.

Mitze, Timo ve Matz, Florian. 2015. "Public debt and growth in German federal states: What can Europe learn?." Journal of Policy Modeling, 37(2), 208-228.

Modigliani, Franco. 1961. "Long-run implications of alternative fiscal policies and the burden of the national debt.” Economic Journal, 730-755.

Panizza, Ugo ve Presbitero, Andrea F. 2013. "Public debt and economic growth in advanced economies: A survey." Swiss Journal of Economics and Statistics, 149(2), 175-204.

Pattillo, Catherine A., Poirson, Helene ve Ricci, Luca A. 2002. "External debt and growth." International Monetary Fund, No. 02/69.

Pedroni, Peter. 2000. "Fully modified OLS for heterogeneous cointegrated panels." Advances in Econometrics, 15, 93-130.

Pesaran, Hashem M. 2004. "General Diagnostic Tests for Cross Section Dependence in Panels." Institute for the Study of Labor (IZA), No. 1240.

Pesaran, Hashem M. 2006. "Estimation and inference in large heterogeneous panels with a multifactor error structure." Econometrica, 74(4), 967-1012.

Pesaran, Hashem M. 2007. "A simple panel unit root test in the presence of cross- section dependence." Journal of Applied Econometrics, 22(2), 265-312.

Pesaran, Hashem M., Shin, Yongcheol ve Smith, Ron P. 1999. "Pooled mean group estimation of dynamic heterogeneous panels". Journal of the American Statistical Association, 94(446), 621-634.

Pesaran, Hashem M. ve Smith, Ron. 1995. "Estimating long-run relationships from dynamic heterogeneous panels." Journal of Econometrics, 68(1), 79-113.

Reinhart, Carmen M., Rogoff, Kenneth S. ve Savastano, Miguel A. 2003. "Debt Intolerance." Brookings Papers on Economic Activity, (1), 1.

Reinhart, Carmen M. ve Rogoff, Kenneth S. 2010. "Growth in a Time of Debt." American Economic Review, 100(2), 573-78.

Romer, Paul M. 1992. "Two strategies for economic development: Using ideas and producing ideas." World Bank Economic Review, 6(Sup 1), 63-91. 
Türkay, M. / Journal of Yasar University, 2020, 15/60, 692-707

Sachs, Jeffrey D. ve Warner, Andrew M. 1997. "Fundamental sources of long-run growth.” American Economic Review, 87, 184-188.

Xavier, Sala-i-Martin. 1997. “I Just Ran Two Million Regressions.” The American Economic Review, 178-183.

Sargent, Thomas J. ve Wallace, Neil. 1981. “Some Unpleasant Monetarist Arithmetic.” Federal Reserve Bank of Minneapolis Quarterly Review, 5(3), 1-17.

Schclarek, Alfredo. 2004. "Debt and Economic Growth in Developing and Industrial Countries." Lund University, No. 2005: 34.

Seghezza, Elena ve Baldwin, Richard E. 2008. "Testing for trade-induced investment-led growth.” Economia Internazionale/International Economics, 61, 507-537.

Solow, Robert M.1956. "A contribution to the theory of economic growth.” Quarterly Journal of Economics, 70 , 65-94.

Teles, Vladimir K. ve Mussolini, Caio Cesar. 2014. "Public debt and the limits of fiscal policy to increase economic growth." European Economic Review, 66, 1-15. 